\title{
An Unexpectedly High Rate of Thrombophilia Disorders in Patients with Superficial Vein Thrombosis of the Lower Extremities
}

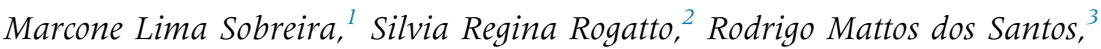 \\ Izolete Thomazini Santos, ${ }^{4}$ Iracema Carvalho Ferrari, ${ }^{5}$ and Winston Bonetti Yoshida, \\ Botucatu, São Paulo, Brazil
}

\begin{abstract}
Background: Superficial vein thrombosis (SVT) is a common venous condition. Recent studies have shown that SVT is associated with high frequency of thromboembolic complications: from $22-37 \%$ for deep venous thrombosis and up to $33 \%$ for pulmonary embolism. Our goal was to assess the prevalence of major hereditary and acquired thrombophilic factors in patients with SVT. Methods: Sixty-six patients presenting with primary SVT underwent evaluation for thrombophilia: molecular testing for the factor V Leiden and factor II G20210 A (prothrombin) mutations, protein $\mathrm{C}$, protein S, antithrombin deficiency, presence of lupus anticoagulant, as well as anticardiolipin antibody titers. Patients aged less than 18 years, with confirmed deep vein thrombosis, and pregnant women were excluded.
\end{abstract}

Results: $95.5 \%$ were Caucasian, and $62.1 \%$ were female gender. Age ranged from $21-88$ years. Molecular testing showed that $34.2 \%$ of patients were heterozygous for factor $\mathrm{V}$ Leiden, $23.6 \%$ were heterozygous for the factor II mutation, $7.8 \%$ had antithrombin deficiency, $2.6 \%$ had protein $\mathrm{S}$ deficiency, and $2.1 \%$ had protein $\mathrm{C}$ deficiency.

Conclusions: Our study showed that hereditary and acquired thrombophilias are higher than previously expected and reported.

\section{INTRODUCTION}

Superficial vein thrombosis (SVT) is a relative common venous condition, easily diagnosed vascular condition, and was considered benign and selflimited. ${ }^{1}$ However, recent studies have shown that, similar to deep venous thrombosis (DVT), ${ }^{2}$ SVT

This work was supported by FAPESP (Sao Paulo Research Foundation) grant number 2007/53958-6.

${ }^{1}$ Division of Vascular and Endovascular Surgery, Department of Surgery and Orthpedics, Botucatu Medical School, UNESP, Botucatu, São Paulo, Brazil.

${ }^{2}$ Department of Urology, Botucatu Medical School, UNESP, Botucatu, São Paulo, Brazil.

${ }^{3}$ Experimental Research Unity (UNIPEX), Botucatu Medical School, UNESP, Botucatu, São Paulo, Brazil.

${ }^{4}$ Hemocentro do Hospital das Clínicas, Botucatu Medical School, UNESP, Botucatu, São Paulo, Brazil.

${ }^{5}$ Coagulation Laboratory, Hemocentro do Hospital das Clínicas, Botucatu Medical School, UNESP, Botucatu, São Paulo, Brazil. may extend and even cause pulmonary embolism $(\mathrm{PE})^{3}$ in up to $33 \%$ of patients. ${ }^{4}$ These data were corroborated by a previous study conducted at our service, ${ }^{5}$ which found a $21.6 \%$ rate of concomitant DVT and a $28.3 \%$ rate of high likelihood of PE in 60 patients admitted consecutively with SVT between the years of 2000 and 2003. Few studies

\footnotetext{
${ }^{6}$ Division of Vascular and Endovascular Surgery, Department of Surgery and Orthpedics, Botucatu Medical School, UNESP, Botucatu, São Paulo, Brazil.

Correspondence to: Marcone Lima Sobreira, Division of Vascular and Endovascular Surgery, Department of Surgery and Orthpedics, Botucatu Medical School, UNESP, 18618-687, Botucatu, São Paulo, Brazil;E-mail:mlsobreira@gmail.com

Ann Vasc Surg 2017; 43: 272-277

http://dx.doi.org/10.1016/j.avsg.2017.02.022

(C) 2017 Elsevier Inc. All rights reserved.

Manuscript received: September 23, 2016; manuscript accepted: February 19, 2017; published online: 10 May 2017
} 
have raised the issue of an association with thrombophilia: the prevalence of factor $\mathrm{V}$ Leiden in these studies ranged from $4.2-14.3 \%$ and that of factor II G20210 A, from 3.6-9.6\%. Deficiency of anticoagulant enzymes (protein $\mathrm{C}$, protein $\mathrm{S}$, and antithrombin) was detected in $5.8-10.2 \%$ of cases, and anticardiolipin antibodies were elevated in $6.7-17.6 \%$ of patients with SVT. The prevalence in the general population varies according to the thrombophilic disorder from $0.02 \%$ (in cases of antithrombin deficiency) to $15 \%$ (factor V Leiden). ${ }^{6-11}$ However, we were unable to find any published reports of systematic assessment to all known thrombophilic factors in patients with SVT. Therefore, the objective of the present study was to ascertain the prevalence of thrombophilic factors, both hereditary (factor V Leiden, factor II G20210 A, protein C deficiency, protein $S$ deficiency, and antithrombin deficiency) and acquired (anticardiolipin antibodies and lupus anticoagulant) in patients with diagnosis of a prior episode of SVT treated at a university hospital in Brazil (Botucatu Medical School), that could be higher than previously reported by other authors. $^{6-11}$

This study was undertaken to evaluate the usefulness of thrombophilia investigation in cases of SVT, in an attempt to understand better the real nature and behavior of the SVT to provide the best clinical approach for these patients.

\section{METHODS}

This cross-sectional study was designed to assess the prevalence of thrombophilia in patients with SVT and was approved by the Botucatu Medical School Research Ethics Committee (protocol number 0478/2006), and its results have not been published yet. All patients agreed to participate in the study and provided written informed consent before blood sample collection. This work was carried out in accordance with The Code of The World Medical Association.

The study sample comprised a group of 66 previously admitted patients with SVT-at the time of diagnosis, all were consecutive outpatients referred to our center. Sixty patients have also been the subject of a previous study published by our group, ${ }^{5}$ plus an additional 6 consecutive patients who had been admitted to our hospital and diagnosed with SVT. Therefore, the final study sample comprised 66 patients. All patients had clinical presentation consistent with thrombophlebitis of the lower extremity, namely, a palpable, hot, and hyperemic cord through a superficial vein or its tributaries. Inclusion criteria were age $>18$ years, and a clinical diagnosis of SVT confirmed by vascular ultrasonography. Exclusion criteria were inflammatory disease and current pregnancy. Blood samples were collected around 5-12 months after acute episode.

All ultrasound examinations were performed using a GE Logiq7 system. Both lower extremities were assessed for the presence and extension of thrombus within the great and small saphenous veins, as well as for the presence of concomitant DVT.

Of the 66 patients, 18 were on anticoagulant therapy due to previous thromboembolic events (prior DVT and/or PE) and also were prescribed by a colleague before referral to our center; therefore, thrombophilia tests dependent on coagulation results were performed on 48/66 patients. Genetic testing was performed on 55/66 patient samples, which had adequate sample quantity and quality. Of these 55 patients, 46 were also tested for PE by high-probability ventilation/perfusion scan or by computed tomography of the lung.

The thrombophilia workup, which was performed at the Coagulation Laboratory of the study institution, consisted of anticardiolipin antibody (IgG and IgM), lupus anticoagulant, protein C, protein $\mathrm{S}$, and antithrombin testing. Coagulation tests (thrombin time, activated partial thromboplastin time [aPTT], and International Normalized Ratio [INR]) were also performed. The Sydney criteria ${ }^{12}$ were used for diagnosis of the antiphospholipid antibody syndrome (APS), with 02 (two) anticardiolipin antibody titers $>40 \mu \mathrm{m} / \mathrm{mL}$ at 12 -week interval.

$\operatorname{IgG}$ and $\operatorname{IgM}$ anticardiolipin antibody testing was performed using commercially available Enzyme Linked Immuno Sorbent Assay (ELISA) kits (EuroImmun, Germany). Protein $\mathrm{C}$ and antithrombin testing were performed by the chromogenic substrate method, in a Sysmex CA-1500 (Siemens Healthcare Diagnostics, Germany). Protein $S$ determination was performed by the sandwich ELISA method (Helena Laboratories). Finally, lupus anticoagulant testing was performed by the aPTT and dilute Russell's viper venom time (dRVVT) assays.

Genetic testing was performed to detect the factor V Leiden and factor II G20210 A mutations in homozygosis and heterozygosis. The DNA was extracted from blood samples by the organic solvent technique, ${ }^{13}$ and the purified DNA was used for polymerase chain reaction (PCR) testing with the following primers:

Factor V Leiden.

5'-TGCCCAGTGCTTAACAAGACCA-3' sense; 
5'-CTTGAAGGAAATGCCCCATTA-3' antisense. Factor II G20210 A.

5'-TCTAGAAACAGTTGCCTGGC-3' sense;

5'-ATAGCACTGGGAGCATTGAAGC- $3^{\prime}$ antisense.

The PCR amplification product for the factor $\mathrm{V}$ gene was treated with the MnlI restriction enzyme, and the products of digestion were visualized by agarose gel electrophoresis. In the presence of the factor $\mathrm{V}$ Leiden mutation, digestion resulted in 2 fragments of $67 \mathrm{bp}$ and $153 \mathrm{bp} .^{14}$

For the prothrombin gene, PCR amplification product was treated with the Hind III restriction enzyme, and the products of digestion visualized by agarose gel electrophoresis. In the presence of the G20210 A mutation, digestion resulted in 2 fragments of $322 \mathrm{bp}$ and $23 \mathrm{bp}^{15,16}$

Statistical analyses (frequencies and measures of central tendency) were performed in Epi Info, version 3.5.1. Fisher's exact test was used for analysis of differences in frequencies. The significance level was set at 5\%.

\section{RESULTS}

\section{Demographic Data}

Demographic data for the 66 patients are shown in Table I. Patients were predominantly of female gender $(41 / 66 ; 62.1 \%)$ rather than male $(25 / 66 ; 37.9 \%)$. Mean age was 53.8 years (median $=53$ years), with a range of $21-88$ years. Patients were mostly Caucasian $(95.5 \%)$, and the most common risk factor was a history of venous thromboembolism $(\mathrm{DVT}=30.2 \%, \mathrm{PE}=16.3 \%)$, followed by varicose veins $(25.8 \%)$, prior surgery $(15.2 \%)$, oral contraceptive use $(4.5 \%)$, and recent pregnancy $(3.0 \%)$. Varicose veins predominated among women, whereas the other risk factors had a similar gender distribution. On average, patients were admitted to our hospital 9 days after symptoms onset. The subgroup of patients who were not on anticoagulant therapy had similar demographic characteristics.

\section{Ultrasound and Nuclear Medicine Findings}

The great saphenous vein was the site of SVT in most patients $(84.4 \%)$, and its involvement was significantly more frequent in women. The small saphenous vein was less commonly affected $(7.8 \%)$. The mean distance from the cutaneous sign of inflammation (palpable, cord like vein) to its probable outlet to the deep venous circulation (at the level of the inguinal or popliteal crease) was $15.9 \mathrm{~cm}$ $($ median $=17.0 \mathrm{~cm})$, with a range of $0-28 \mathrm{~cm}$.
Table I. Demographic and clinical profile of 66 patients with superficial vein thrombosis treated at our University Hospital and included in the study

\begin{tabular}{ll}
\hline Variables & Total $(n=66)$ \\
\hline Mean/median age (years) & $53.8 / 53.0$ \\
Age range (years) & $21-88$ \\
Skin color: white/black/brown & $95.5 / 1.5 / 3.0 \%$ \\
Mean time since ST onset & 9 days \\
History & \\
$\quad$ Trauma & $1.5 \%(n=1)$ \\
Prior DVT & $30.2 \%(n=20)$ \\
Prior PE & $10.6 \%(n=7)$ \\
Current pregnancy & $3.0 \%(n=2)$ \\
$\quad$ Surgery & $15.2 \%(n=10)$ \\
$\quad$ Rest & \\
Hormonal contraception & $1.5 \%(n=1)$ \\
Varicose veins $_{\text {Prior phlebitis }}$ & $4.5 \%(n=3)$ \\
Prion & $25.8 \%(n=17)$ \\
\hline
\end{tabular}

${ }^{\text {a }}$ Range time 30 days.

Table II. Results of thrombophilia workup in 66 patients with superficial vein thrombosis of the lower limbs

\begin{tabular}{lcc}
\hline Test & $\begin{array}{c}\text { Frequency } \\
(\%)\end{array}$ & $n$ \\
\hline Factor V Leiden, homozygous & 0.0 & 55 \\
Factor V Leiden, heterozygous & 46.4 & 55 \\
Factor II G20210 A homozygous & 0.0 & 56 \\
Factor II G20210 A, heterozygous & 21.4 & 56 \\
Antithrombin deficiency & 6.25 & 48 \\
Protein C deficiency & 2.1 & 48 \\
Protein S deficiency & 6.2 & 48 \\
Lupus anticoagulant, positive & 0.0 & 48 \\
Anticardiolipin IgG >40 & 0.0 & 65 \\
Anticardiolipin IgM $>40$ & 0.0 & 65 \\
\hline
\end{tabular}

Values are expressed as relative frequencies.

The distance from the distal portion of the intravenous thrombus to the saphenofemoral junction, as assessed ultrasonographically, was $8.04 \mathrm{~cm}$ (median $=4.75 \mathrm{~cm}$ ), with a range of $0-26 \mathrm{~cm}$. In $10.7 \%$ of cases, there was concomitant DVT ipsilateral to the ST. In $19.6 \%$ of cases, there was concomitant PE.

In the subgroup of patients who were not on anticoagulant therapy $(n=48), 85.1 \%$ had GSV involvement, $8.5 \%$ has SSV involvement, the mean ultrasound distance was $7.2 \mathrm{~cm}$, and the mean distance to the saphenofemoral junction was $16.0 \mathrm{~cm}$. 
Table III. Prevalence of factors associated with thrombophilia in previous studies of patients with superficial vein thrombosis

\begin{tabular}{|c|c|c|c|c|c|c|c|c|c|c|}
\hline \multirow[b]{2}{*}{ Author } & \multirow[b]{2}{*}{ Year } & \multirow[b]{2}{*}{$n$} & \multirow{2}{*}{$\begin{array}{l}\text { Factor } \\
\text { V Leiden }\end{array}$} & \multirow{2}{*}{$\begin{array}{l}\text { Factor II } \\
\text { G20210 A }\end{array}$} & \multirow{2}{*}{$\begin{array}{l}\text { Protein C } \\
\text { deficiency }\end{array}$} & \multirow{2}{*}{$\begin{array}{l}\text { Protein S } \\
\text { deficiency }\end{array}$} & \multirow{2}{*}{$\begin{array}{l}\text { Antithrombin } \\
\text { deficiency }\end{array}$} & \multicolumn{2}{|c|}{ Anticardiolipin antibodies } & \multirow[b]{2}{*}{ Association } \\
\hline & & & & & & & & $\operatorname{IgG}$ & $\operatorname{Ig} M$ & \\
\hline De Moerloose ${ }^{6}$ & 1998 & 112 & 14.3 & 3.6 & NA & NA & NA & NA & NA & - \\
\hline $\mathrm{McColl}^{7}$ & 1998 & 24 & 4.2 & 0.0 & NA & NA & NA & NA & NA & - \\
\hline Martinelli $^{8}$ & 1999 & 63 & 15.9 & 9.6 & 10.2 & & & NA & NA & \\
\hline Hanson ${ }^{9}$ & 1998 & 17 & 5.8 & 0.0 & 5.8 & & & 17.6 & 17.6 & 33.0 \\
\hline de Godoy ${ }^{10}$ & 2001 & 45 & NA & NA & NA & NA & NA & 26.7 & 6.7 & - \\
\hline de Godoy ${ }^{11}$ & 2003 & 36 & NA & NA & NA & 5.5 & NA & NA & NA & - \\
\hline Present study & 2013 & 66 & 46.4 & 21.4 & 2.1 & 6.8 & 2.1 & 0.0 & 0.0 & \\
\hline
\end{tabular}

Values are expressed as relative frequencies.

$\mathrm{NA}=$ not assessed.

\section{Thrombophilia Findings}

Of the thrombophilic factors investigated, factor $\mathrm{V}$ Leiden mutations were the most common, being detected in $26 / 55(46.4 \%)$ of patients. Factor II mutation G20210 A was detected in 12/56 $(21.4 \%)$ of patients (Table II). Mutations were always heterozygous.

None of the patients were positive for lupus anticoagulant. Three patients had anticardiolipin antibody titers above the reference range of $12.0 \mu \mathrm{m} / \mathrm{mL}$; being the titers 17,20 , and $30 \mu \mathrm{m} /$ $\mathrm{mL}$. None of these patients met consensus criteria $(>40.0 \mu \mathrm{m} / \mathrm{mL})$ for diagnosis of APS. Seven patients $(7 / 48,15.0 \%)$ had deficiency of anticoagulant proteins: 3 had protein $\mathrm{S}$ deficiency, 1 had protein $\mathrm{C}$ deficiency, and 3 had antithrombin deficiency.

It should be highlighted that among patients with varicose veins $(25.8 \%$-Table I), thrombophilia screening was possible to be performed in $80.9 \%$ of them and was positive in $27.6 \%$ (unexpectedly high rate). By the other hand, among patients without varicose veins, the search for thrombophilia was performed in $87.7 \%$ and resulted positive in $53.4 \%$. Malignant disease was present in 05 patients (7.5\%): 04 patients without varicose veins and 01 at patients with varicose veins. Immobilization (as risk factor) was not present in none of the included patients.

\section{DISCUSSION}

This single-center sample included patients who were consecutively admitted to the Vascular Surgery unit of a university hospital with a suspected diagnosis of ST, which was later confirmed by clinical and ultrasonography examination. In 60 patients, prevalence of PE and DVT was $28.3 \%$ and $21.67 \%$, respectively, ${ }^{5}$ therefore the prevalence of thrombophilia may be higher than in other SVT populations. Genetic testings were performed according to laboratory standards with same sensitivity as described of previous reports. ${ }^{13-16}$

Preferential involvement of the great saphenous vein $(84.4 \%)$ and the female predominance of the sample $(62.1 \%)$ was consistent with the current literature. The incidence of DVT was similar to that reported in several previous studies, which ranged from $8.3-36.0 \%$ depending on the presence of varicose veins. ${ }^{4}$ The incidence of venous thromboembolism could not be assessed in all patients, but in those tested for this condition, there was a substantial frequency $(19.6 \%)$ of high risk for PE. In a previous study by our group, this incidence was even higher $(28.3 \%),{ }^{5}$ whereas in the literature, the rate ranged from 3-33\%. ${ }^{4}$ These findings confirmed that thromboembolic complication rates persisted as high as to the literature data. ${ }^{3,4}$ Clinical and ultrasonography measurements of thrombophlebitis extent were similar to those obtained in our previous study, and ultrasound measurements were more precise than physical examination. ${ }^{5}$

Few previous studies (Table III) addressed the presence of thrombophilic factors in patients with ST. Furthermore, none assessed all the relevant factors that can currently be measured in patients with thrombophilia. Therefore, the present study was the first to conduct a systematic, simultaneous assessment of all known major thrombophilic factors in a larger, single-center population of patients with SVT.

In previous studies, deficiency of anticoagulant proteins affected $5.8-10.2 \%$ of patients (Table III). De Godoy et al. found a 5.5\% rate of protein $\mathrm{S}$ deficiency in a group of 36 patients. Hanson et al. and De Godoy et al. found anticardiolipin IgG antibodies in $17.6-26.7 \%$ of cases, and IgM antibodies in $6.7-17.6 \%$, respectively. 
Anticardiolipin antibodies were present in $17.9 \%$ of patients in the Hansen et al. sample $(n=17)$, but one must consider that, according to the Sydney criteria, $^{12} 2$ consecutive measurements of IgG or IgM titers $>40 \mu \mathrm{m} / \mathrm{mL}$, obtained 12 weeks apart, are required to confirm a diagnosis of APS. Furthermore, the timing of blood collection plays a major role in these assays, which may yield false-positive results when performed too soon after acute disease. Factor V Leiden was the predominant mutation in the previous studies reviewed, affecting $4.2-15.9 \%$ of cases, whereas the prothrombin mutation was found in 3.6-9.6\%. (Table III).

The prevalence of thrombophilia in the general population (free of thromboembolic disorders) was quite low for protein deficiency disorders, but it can reach higher frequencies for factor $\mathrm{V}$ Leiden: protein deficiencies are $0.02-0.4 \%$; that of factor V Leiden, 1.15-15.0\%; and that of the prothrombin mutation, approximately $5 \% .{ }^{17}$ In patients with DVT, the prevalence of these conditions is $1-5 \%, 10-58 \%$, and $6-18 \%$ respectively. ${ }^{17}$ The prevalence of lupus anticoagulant and APS in the general population ranges from $5-7 \%,{ }^{18}$ whereas in patients with DVT, it is $25-30 \%$. The sample sizes of previous studies of SVT patients have varied widely, ranging from 17-112 cases. The tests performed on these patients have also varied across studies, but some findings have been consistently expressive, such as a frequency of coagulation protein deficiencies higher than that found in DVT patients. In our cohort of patients with SVT, we found a prevalence of factor V Leiden mutation similar to the general population, whereas the frequency of the prothrombin mutation was higher than that of the general population and lower than that seen in DVT patients (Table III).

In our patient cohort, the prevalence of coagulation protein deficiencies $(15.0 \%)$ was higher than literature data on patients diagnosed with SVT and/or DVT. In addition, our sample size was larger compared with previous literature data (Table III). Although, none of our patients tested positive for anticardiolipin antibodies or lupus anticoagulant. Titers slightly above the reference range were insufficient to meet international criteria for diagnosis of APS $(>40.0 \mu \mathrm{m} / \mathrm{mL})^{12}$; in our sample, anticardiolipin antibody titers ranged from $2.0-10.0 \mu \mathrm{m} / \mathrm{mL}$ for IgG and from $2.0-30.0 \mu \mathrm{m} / \mathrm{mL}$ for IgM.

On the other hand, we found a high prevalence of factor V Leiden $(47.3 \%)$ and prothrombin mutation $(21.4 \%)$ in our patient population diagnosed with SVT. These findings are novel in patients with SVT and consistent with previous studies of patients with only DVT.
Although varicose vein is a known risk factor for DVT and SVT, we have no explanation to justify the high prevalence of thrombophilia disorders in these patients.

Notwithstanding our results show a high rate for thrombophilic disorders in SVT, there is no enough evidence to justify a broad investigation for these patients. Searching for thrombophilia and malignancy is recommended only for patients with spontaneous SVT in patients without varicose veins or recurrent SVT in patients with varicose veins. ${ }^{19,20}$

We recognize that both the lack of a control group (saving costs) and the inability to screen all patients for thrombophilia are limitations of our study. Besides that, $46 \%$ of our sample had a prior episode of DVT or $\mathrm{PE}$, addressing a selection bias for this study.

\section{CONCLUSIONS}

The present study of patients with SVT found a high prevalence of thromboembolic complications (DVT and PE) and found that SVT was frequently associated with hereditary thrombophilias, namely coagulation protein deficiencies (antithrombin, protein $\mathrm{C}$, and protein $\mathrm{S}$ deficiency) and factor $\mathrm{V}$ and II gene mutations. Our results showed that SVT increases the likelihood of identifying a hypercoagulable state, more severe than previously linked to this entity. However, other studies are warranted to prove this hypothesis. In spite of the high prevalence of thrombophilic disorders, even in patients with varicose veins, more studies are warranted to state a broad investigation in SVT patients.

The authors thank nursing aide Terezinh Fatima Barros, nurse Mauricia Vidal, and biomedical scientist Elizaide L.A. Yoshida for locating patients and collecting blood samples and residents Paloma Guerra, Érika Bonfietti, and Jamil Mariúba for verifying results and conducting chart reviews. The authors also thank Dr. Patricia Reis for constructive criticism and careful reading of the article.

\section{REFERENCES}

1. Decousus H, Quere I, Presles E, et al. Superficial venous thrombosis and venous thromboembolism: a large, prospective epidemiologic study. Ann Intern Med 2010;152:218-24.

2. Blumenberg RM, Barton E, Gelfand ML, et al. Occult deep venous thrombosis complicating superficial thrombophlebitis. J Vasc Surg 1998;27:338-43.

3. Verlato F, Zucchetta P, Prandoni P, et al. An unexpectedly high rate of pulmonary embolism in patients with superficial thrombophlebitis of the thigh. J Vasc Surg 1999;30: $1113-5$. 
4. Sobreira ML, Yoshida WB, Lastoria S. Superficial thrombophlebitis: epidemiology, pathophysiology, diagnosis and treatment. J Vasc Bras 2008;7:131-43.

5. Sobreira ML, Maffei FH, Yoshida WB, et al. Prevalence of deep vein thrombosis and pulmonary embolism in superficial thrombophlebitis of the lower limbs: prospective study of 60 cases. Int Angiol 2009;28:400-8.

6. de Moerloose P, Wutschert R, Heinzmann M, et al. Superficial vein thrombosis of lower limbs: influence of factor V Leiden, factor II G20210A and overweight. Thromb Haemost 1998;80:239-41.

7. McColl MD, Ramsay JE, Tait RC, et al. Superficial vein thrombosis: incidence in association with pregnancy and prevalence of thrombophilic defects. Thromb Haemost $1998 ; 79: 741-2$.

8. Martinelli I, Cattaneo M, Taioli E, et al. Genetic risk factors for superficial vein thrombosis. Thromb Haemost 1999;82: $1215-7$.

9. Hanson JN, Ascher E, DePippo P, et al. Saphenous vein thrombophlebitis (SVT): a deceptively benign disease. J Vasc Surg 1998;27:677-80.

10. de Godoy JM, Batigalia F, Braile DM. Superficial thrombophlebitis and anticardiolipin antibodies-report of association. Angiology 2001;52:127-9.

11. de Godoy JM, Braile DM. Protein S deficiency in repetitive superficial thrombophlebitis. Clin Appl Thromb Hemost 2003;9:61-2.

12. Miyakis S, Lockshin MD, Atsumi T, et al. International consensus statement on an update of the classification criteria for definite antiphospholipid syndrome (APS). J Thromb Haemost 2006;4:295-306.

13. Kirby GM, Batist G, Fotouhi-Ardakani N, et al. Allele-specific PCR analysis of p53 codon 249 AGT transversion in liver tissues from patients with viral hepatitis. Int $\mathrm{J}$ Cancer 1996;68:21-5.

14. Bertina RM, Koeleman BP, Koster $\mathrm{T}$, et al. Mutation in blood coagulation factor $\mathrm{V}$ associated with resistance to activated protein C. Nature 1994;369:64-7.

15. Poort SR, Rosendaal FR, Reitsma PH, et al. A common genetic variation in the $3^{\prime}$-untranslated region of the prothrombin gene is associated with elevated plasma prothrombin levels and an increase in venous thrombosis. Blood 1996;88: 3698-703.

16. Franco RF, Trip MD, ten Cate H, et al. The 20210 G->A mutation in the 3'-untranslated region of the prothrombin gene and the risk for arterial thrombotic disease. Br J Haematol 1999; 104:50-4.

17. Franco RF. Trombofilias hereditárias. In: Maffei FHAea ed. Doenças vasculares periféricas. São Paulo: Gen, 2008. pp 1579-88.

18. Franco RF. Trombofilias adquiridas. In: Maffei FHAea ed. Doenças vasculares periféricas. São Paulo: Gen, 2008. pp 1589-96.

19. De Maeseneer MGR. Superficial thrombophlebitis of the lower limb: practical recommendations for diagnosis and treatment. Acta Chir Belg 2005;105:145-7.

20. kalodiki E, Stvrtinova V, Allegra C, et al. Superficial vein thrombosis: a consensus statement. IntAngiol 2012;31:203-16. 